УСТИНКИН Сергей Васильевич - доктор исторических наук, профессор; декан факультета международных отношений, экономики и управления, профессор кафедры международных отношений и политологии Нижегородского государственного лингвистического университета им. Н.А. Добролюбова (603155, Россия, г. Нижний Новгород, ул. Минина, 31а); директор Приволжсккого филиала ФНИСЦ РАН (603000, Россия, г. Нижний Новгород, пер. Холодный, 4; sv.ustinkin@gmail.com)

КУКОНКОВ Павел Иванович - кандидат социологических наук, старший научный сотрудник Приволжсккого филиала ФНИСЦ РАН ((603000, Россия, г. Нижний Новгород, пер. Холодный, 4; kukonkov_pavel@rambler.ru)

МОРОЗОВА Наталья Михайловна - кандидат политических наук, доцент кафедры международных отношений и политологии Нижегородского государственного лингвистического университета им. Н.А. Добролюбова (603155, Россия, г. Н.Новгород, ул. Минина, 31а); заместитель директора Приволжского филиала ФНИСЦ РАН (603000, Россия, г. Нижний Новгород, пер. Холодный, 4; 4379037@gmail.com)

\title{
МИГРАЦИОННАЯ НАГРУЗКА В РЕГИОНАХ ПФО: МАСШТАБЫ И СЛЕДСТВИЯ
}

Аннотация. Анализ социальной ситуации внутри российских регионов требует не только внимания к процессам адаптации мигрантов, но и особого взгляда на эти проблемы с позиции принимающего сообщества с присущей ему культурой и традициями. Авторы статьи обосновывают подход, в соответствии с которым миграционная политика должна быть скоординирована с планами развития сети социальных учреждений, и анализируют, насколько эффективно осуществляется такая координация на примере ПФО и Нижегородской обл. Авторы приходят к выводу, что значительные масштабы неконтролируемых миграционных потоков в сочетании с нерешенностью проблем жизнеобеспечения значительной части принимающего населения не только негативно сказываются на социально-экономической и политической ситуации в регионе, но и требуют совершенствования механизмов взаимодействия населения с государством, способных эффективно влиять на решение подобных проблем.

Ключевые слова: социальные процессы, социальное напряжение, социальный конфликт, социальное противоречие, миграция, миграционная политика, принимающее сообщество

$\mathrm{H}$ а рубеже XX-XXI вв. среди глобализационных процессов на передний план выдвинулась проблема миграции, изменяющая политическую, экономическую, социокультурную ситуацию во многих государствах. Актуализируется целый комплекс проблем, связанных с интенсификацией миграционных процессов, предпринимаются попытки оптимизировать эти процессы. Так, 13 июля 2018 г. агентство ООН по миграции объявило о завершении Глобального договора о миграции в качестве важной вехи, которая улучшит международное сотрудничество в области миграции 1 . Вместе с тем достаточно очевидно, что негативные последствия миграционных процессов усиливаются.

Россия все глубже втягивается в процесс глобализации, который неизбежно усиливает «экономическую власть» крупных международных и российских корпораций в регионах России, смещая за пределы региона и зачастую государства центры принятия важных решений в социальной сфере.

Следует подчеркнуть, что указанные процессы, сопровождаемые слабо контролируемыми миграционными потоками, оказывают дестабилизирующее влияние на социальную ситуацию внутри регионов. Мы разделяем подход, в соответствии с которым добросовестный и ответственный анализ социальной

1 Генеральный директор Агентства по миграции ООН Свинг приветствует «исторический» Глобальный договор о миграции. - МОМ. Доступ: http://www.iom.int/news (проверено10.07.2018). 
ситуации внутри регионов предполагает не только внимание к процессам адаптации мигрантов, но и особый взгляд на эти проблемы с позиции принимающего сообщества с присущей ему культурой и традициями [Дмитриев, Воронов 2017: 10].

Следует подчеркнуть, что связь миграционных процессов с ситуацией в социальной сфере региона требует особого внимания, которое до сих пор не адекватно ее значимости в жизни регионов. Недостаток внимания к этой проблеме в определенной мере объясняется наличием теоретико-методологических проблем, в частности непониманием особенностей связи между масштабами и последствиями миграционных потоков, выражающихся прежде всего в росте миграционной нагрузки на социальную сферу принимающего сообщества.

Указ Президента РФ «О национальных целях и стратегических задачах развития РФ на период до 2024 года» содержит в числе главных поручений правительству РФ обеспечение устойчивого естественного роста численности населения Российской Федерации, обеспечение роста ожидаемой продолжительности жизни до 78 лет и увеличение суммарного коэффициента рождаемости до 1,71. Вместе с тем в январе-апреле 2018 г. число родившихся в России составило 96,4\% к уровню 2017 г., число умерших в этот период составило $100,8 \%$ к соответствующему периоду прошлого года 2 . Прирост численности населения наблюдается лишь в республиках Кавказа (Адыгея, Ингушетия, Чеченская республика) и в наиболее богатых регионах РФ (Московская обл., Краснодарский край, Ханты-Мансийский АО, Тюменская обл.) ${ }^{3}$. Следует подчеркнуть, что общее увеличение численности населения России обеспечивается миграционным приростом ${ }^{4}$.

В ряде российских регионов демографическая проблема является одной из весьма острых. К числу таких регионов относится Приволжский федеральный округ (ПФО) - один из самых населенных регионов России (29 636,5 тыс. чел.), занимающий 2-е место по численности населения после ЦФО (39 209,6 тыс. чел. $)^{5}$. Обращает на себя внимание то, что, являясь одним из лидеров по численности населения, числу занятых и по объему валового регионального продукта, ПФО находится в числе аутсайдеров по уровню доходов (расходов) и среднемесячной номинальной начисленной заработной плате 6 .

Значительные различия социально-экономических характеристик субъектов РФ, свидетельствующие о слабом регулировании социальных процессов, сказываются на направленности миграционных потоков внутри страны. В этом отношении основные субъекты РФ могут быть разделены на две группы: субъекты, в которых последние годы наблюдается стабильный миграционный прирост (ЦФО, СЗФО, ЮФО, УрФО), и субъекты, в которых фиксируется постоянная миграционная убыль населения (СКФО, ПФО, СФО, ДВФО) 7 . Следует

\footnotetext{
1 Указ Президента РФ от 07.05.2018 «О национальных целях и стратегических задачах развития Российской Федерации на период до 2024 года». Доступ: https://worknet-info.ru/read-blog/1365 (проверено 02.10.2018).

2 Естественное движение населения в разрезе субъектов РФ за январь-апрель 2018 года. Федеральная служба государственной статистики. Официальный сайт. Доступ: http://www.gks.ru/wps/ wcm/connect/rosstat_main/rosstat/ru/statistics/population/demography (проверено 04.08.2018).

3 Демография: Изменение численности населения РФ за 2016 г. - Федеральная служба государственной статистики. Официальный сайт. Доступ: http://www.gks.ru/wps/wcm/connect/rosstat_main/rosstat/ ru/statistics/population/demography/ (проверено 11.07.2018).

4 Там же.

5 Регионы России. Социально-экономические показатели: статистический сборник. М.: Росстат. 2017. C. 18 .

6 Там же. С. 18-19.

7 Там же. С. $85-86$.
} 
отметить, что миграционный прирост в регионах первой группы обеспечивается как за счет других субъектов РФ, так и за счет миграции из стран СНГ и дальнего зарубежья.

На наш взгляд, характер и направленность миграционных потоков не только являются важными показателями благополучия социальной ситуации в регионе, но и выступают в качестве необходимой составляющей интегральной оценки состояния социальной сферы. В связи с этим весьма симптоматично создание в Башкортостане рабочей группы, в обязанности которой будет входить именно регулирование процессов миграции населения 1 .

В 2005-2016 гг. миграционная убыль населения наблюдалась в большинстве регионов ПФО. Исключение составляли Татарстан, Нижегородская и Самарская обл. ${ }^{2}$ В начале 2018 г. миграционная убыль населения наблюдается уже во всех регионах округа, в т.ч. и в тех, где она отсутствовала еще год назад. В начале 2018 г. наибольшая убыль населения среди регионов ПФО наблюдалась в Нижегородской обл., Мордовии, Саратовской и Ульяновской обл. (см. табл. 1).

Таблица 1

Естественный прирост, убыль населения в регионах ПФО в начале 2018 г.

\begin{tabular}{|c|c|c|}
\hline \multirow{2}{*}{ Регионы } & \multicolumn{2}{|c|}{ Январь-май 2018 г. } \\
\hline & чел. & на 1000 чел. населения \\
\hline Приволжский федеральный округ & -44297 & $-3,6$ \\
\hline Республика Башкортостан & -2483 & $-1,5$ \\
\hline Республика Марий Эл & -773 & $-2,8$ \\
\hline Республика Мордовия & -2013 & $-6,1$ \\
\hline Республика Татарстан & -776 & $-0,5$ \\
\hline Удмуртская Республика & -1040 & $-1,6$ \\
\hline Чувашская Республика & -1534 & $-3,0$ \\
\hline Пермский край & -3299 & $-3,1$ \\
\hline Кировская область & -3120 & $-5,8$ \\
\hline Нижегородская область & -8273 & $-6,2$ \\
\hline Оренбургская область & -2629 & $-3,2$ \\
\hline Пензенская область & -4027 & $-7,3$ \\
\hline Самарская область & -5782 & $-4,3$ \\
\hline Саратовская область & -5727 & $-5,6$ \\
\hline Ульяновская область & -2821 & $-5,4$ \\
\hline
\end{tabular}

Источник: Демография: Естественное движение населения. - Федеральная служба государственной статистики. Официальный сайт. Доступ: http://www.gks.ru/wps/wcm/connect/rosstat_main/rosstat/ru/ statistics/population/demography/ (проверено 10.07.2018).

\footnotetext{
${ }^{1}$ Башкортостан испытывает мощную миграционную нагрузку. - Great-Income: ежедневный бизнесвестник. Доступ: http://great-income.ru (проверено 03.08.2018).

2 Статистика Приволжского федерального округа: статистический сборник № 9. Федеральная служба государственной статистики. Саранск. 2016. С. 18.
} 
В Нижегородской обл. число родившихся в январе-мае 2018 г. по сравнению с соответствующим периодом 2017 г. уменьшилось на 797 чел., а число умерших увеличилось на 846 чел., прибыли 11706 чел. и выбыли 12 308. Область имеет отрицательное сальдо миграции, которое составляет 602 чел. ${ }^{1}$

Характер и направленность изменения численности населения Нижегородской обл. и г. Нижнего Новгорода представлены в табл. 2.

Таблица 2

\section{Компоненты изменения численности населения Нижегородской обл. и г. Нижнего Новгорода в 2016 г., чел.}

\begin{tabular}{|l|c|c|c|c|}
\hline \multicolumn{1}{|c|}{ Показатели } & $\begin{array}{c}\text { Все } \\
\text { население }\end{array}$ & $\begin{array}{c}\text { Городское } \\
\text { население }\end{array}$ & $\begin{array}{c}\text { Сельское } \\
\text { население }\end{array}$ & $\begin{array}{c}\text { Нижний } \\
\text { Новгород }\end{array}$ \\
\hline $\begin{array}{l}\text { Численность населения } \\
\text { области на 01.01.2016 г. }\end{array}$ & 3260267 & 2590817 & 669450 & 1266871 \\
\hline Число родившихся & 38678 & 32639 & 6039 & 16357 \\
\hline Число умерших & 50098 & 37852 & 12246 & 17668 \\
\hline Естественная убыль & -11420 & -5213 & -6207 & -1311 \\
\hline Миграционный прирост & -1134 & -4000 & 2866 & -3894 \\
\hline Общий прирост & -12554 & -9213 & -3341 & -5205 \\
\hline $\begin{array}{l}\text { Численность населения области на } \\
\text { 01.01.2017 г. }\end{array}$ & 3247713 & 2581604 & 666109 & 1261666 \\
\hline $\begin{array}{l}\text { Среднегодовая численность } \\
\text { населения области за 2016 г. }\end{array}$ & 3253990 & 2586210 & 667780 & 1264269 \\
\hline
\end{tabular}

Источник: Компоненты изменения численности населения Нижегородской области и г. Нижнего Новгорода в 2016 году (человек). - Территориальный орган государственной статистики по Нижегородской области. Официальный сайт. Доступ: http://nizhstat.gks.ru/wps/wcm/connect/rosstat_ts/ nizhstat/ru/statistics/population/ (проверено 04.08.2018).

Таким образом, общая убыль населения в Нижегородской обл. на 1 января 2016 г. составила 12554 чел., большая часть которой (9 213 чел.) приходится на городское население и почти половина (5 205) - на Нижний Новгород.

Слабо контролируемый рост миграционных потоков может оказать непрогнозируемое воздействие на демографическую нагрузку. В ПФО в условиях миграционной убыли наблюдается рост коэффициента демографической нагрузки: в 2016 г. на 1000 чел. трудоспособного возраста приходилось 787 лиц нетрудоспособных возрастов (в РФ - 764). Демографическая нагрузка выше только в Южном федеральном округе (789) и заметно меньше в Северокавказском (715) и в Дальневосточном федеральных округах (712). Для сравнения, в Кировской обл. ПФО демографическая нагрузка составила 867, в Пензенской области - 813, Удмуртии - 804, Оренбургской обл. -802 , Пермском крае -800 , Нижегородской обл. $-793^{2}$.

Масштаб и динамика миграционной нагрузки на население региона (числен-

1 Демографическая ситуация в январе-мае 2018. - Территориальный орган государственной статистики по Нижегородской области. Официальный сайт. Доступ: http://nizhstat.gks.ru/wps/wcm/ connect/rosstat_ts/nizhstat/ru/statistics/population/ (проверено 03.08.2018).

2 Регионы России. Социально-экономические показатели: статистический сборник. М.: Росстат. 2017. C. 52 . 
ность мигрантов в расчете на 10 тыс. чел. населения) неизбежно сказываются на демографической нагрузке и могут принимать выраженное негативное значение в случае избыточного присутствия мигрантов на рынке труда и увеличения среди них доли нетрудоспособных возрастных групп.

Присутствие мигрантов предполагает использование ими социальной инфраструктуры (дороги, транспорт, детские, медицинские учреждения), в создании и развитии которой они не принимали участия и в значительной мере не намерены это делать. Вместе с тем экспертные оценки свидетельствуют, что совокупные потери казны от неуплаты налогов мигрантами превышают 117 млрд руб. в год ${ }^{1}$. Следует отметить, что значительная часть работодателей и иммигрантов налоги не платят. При этом они пользуются всей инфраструктурой, содержащейся на государственные деньги.

Представляется бесспорным, что государственная миграционная политика должна учитывать не только существующий уровень миграционной нагрузки и естественное движение населения (прирост, убыль), но и тесно связанные с ними характеристики социальной ситуации в конкретном регионе. Мы разделяем подход, в соответствии с которым миграционная политика должна быть скоординирована с планами развития сети социальных учреждений ${ }^{2}$.

Насколько эффективно осуществляется такая координация, рассмотрим на примере ПФО и Нижегородской обл. В ходе выборочного обследования Нижегородоблстата в 2016 г. нижегородцы указали наиболее острые проблемы, связанные с условиями проживания ${ }^{3}$ : состояние дорог, безопасность дорожного движения $(62,9 \%)$, плохая организация работы жилищно-коммунальных служб $(41,5 \%)$, недоступность государственных и муниципальных услуг в сфере медицинского обслуживания $(36,6 \%)$.

Мы предполагаем, что присутствие большого числа нелегальных мигрантов не столько облегчает указанные проблемы принимающего населения, сколько усложняет их решение. При этом миграционная нагрузка ложится прежде всего на плечи низкодоходных групп населения, вынужденных пользоваться услугами имеющейся социальной инфраструктуры совместно с мигрантами. В связи с этим весьма показателен уровень среднедушевых денежных доходов принимающего населения и, прежде всего, численность групп населения, имеющих среднедушевые денежные доходы ниже величины прожиточного минимума.

Нижегородская обл. по среднедушевым денежным доходам населения занимает далеко не лидирующие позиции в ПФО:

- по численности населения, имеющего денежные доходы ниже среднедушевого денежного дохода, - на 4-м месте;

- по численности населения, имеющего денежные доходы ниже модального среднедушевого денежного дохода, - на 10-м месте;

- по численности населения, имеющего среднедушевые денежные доходы ниже величины прожиточного минимума, - на 13-м месте (см. табл. 3).

\footnotetext{
1 Анастасия Башкатова. Экономика РФ терпит убытки из-за нелегалов. Инвестиционно привлекательные регионы притягивают гастарбайтеров. - Независимая газета. 17.10.2013. Доступ: http://www. ng.ru/economics/2013-10-17/1_illegal.html (проверено 03.08.2018).

2 «Легальные мигранты не должны быть обречены на положение изгоев». Из выступления Сергея Нарышкина на круглом столе «Открытая трибуна»: Межнациональные отношения и миграционный контроль: проблемы и пути решения». - Парламентская газета. 18.10.2012.

3 Итоги комплексного наблюдения условий жизни населения в 2016 году. Мнение об условиях проживания в населенном пункте. - Территориальный орган государственной статистики по Нижегородской области. Уровень жизни. Официальная статистика. 19.12.2017. Доступ: http://nizhstat. gks.ru/wps/wcm/connect/rosstat_ts/nizhstat/ru/statistics/standards_of_life/ (проверено 04.08.2018).
} 
Таблица 3

Среднедушевые денежные доходы населения в субъектах ПФО за 2017 г. (в \% к общей численности населения)

\begin{tabular}{|c|c|c|c|}
\hline \multirow[b]{2}{*}{ Регионы } & \multicolumn{2}{|c|}{$\begin{array}{l}\text { Численность населения, имеющего } \\
\text { среднедушевые денежные доходы }\end{array}$} & \multirow{2}{*}{$\begin{array}{c}\text { Численность } \\
\text { населения, имеющего } \\
\text { среднедушевые } \\
\text { денежные доходы ниже } \\
\text { величины прожиточного } \\
\text { минимума }\end{array}$} \\
\hline & $\begin{array}{c}\text { ниже } \\
\text { среднедушевого } \\
\text { денежного } \\
\text { дохода }\end{array}$ & $\begin{array}{c}\text { ниже } \\
\text { модального } \\
\text { среднедушевого } \\
\text { денежного } \\
\text { дохода } \\
\end{array}$ & \\
\hline Башкортостан & 65,1 & 22,0 & 12,3 \\
\hline Марий Эл & 63,2 & 25,0 & 22,8 \\
\hline Мордовия & 62,9 & 25,5 & 18,9 \\
\hline Татарстан & 64,5 & 22,9 & 7,7 \\
\hline Удмуртия & 63,3 & 24,9 & 12,5 \\
\hline Чувашия & 62,1 & 26,8 & 19,0 \\
\hline Пермский край & 64,7 & 22,6 & 15,1 \\
\hline Кировская область & 62,3 & 26,6 & 16,0 \\
\hline Нижегородская область & 64,4 & 23,1 & 9,9 \\
\hline Оренбургская область & 63,8 & 24,0 & 14,5 \\
\hline Пензенская область & 62,8 & 25,6 & 14,6 \\
\hline Самарская область & 63,6 & 24,3 & 13,6 \\
\hline Саратовская область & 62,9 & 25,5 & 17,4 \\
\hline Ульяновская область & 63,0 & 25,4 & 15,1 \\
\hline
\end{tabular}

Представляется вполне закономерным, что большинство работающих нижегородцев не удовлетворены заработком по месту своей основной работы. Наиболее высок этот показатель в сельской местности - здесь более $80 \%$ заявили о неудовлетворенности заработком (см. табл. 4).

Таблица 4

Удовлетворенность нижегородцев заработком на основной работе, \%

\begin{tabular}{|l|c|c|c|c|c|}
\hline \multicolumn{1}{|c|}{ Заработок } & Всего & Мужчины & Женщины & Город & Село \\
\hline Вполне удовлетворены & 32,3 & 34,3 & 30,1 & 35,1 & 19,6 \\
\hline Не вполне удовлетворены & 53,5 & 51,4 & 55,7 & 51,2 & 63,8 \\
\hline Совсем не удовлетворены & 14,2 & 14,3 & 14,1 & 13,7 & 16,6 \\
\hline
\end{tabular}

Источник: Итоги комплексного наблюдения условий жизни населения в 2016 году. Удовлетворенность работой по социально-экономическим категориям. - Территориальный орган государственной статистики по Нижегородской области. Уровень жизни. Официальная статистика. 21.12.2017. Доступ: http://nizhstat.gks.ru/wps/wcm/connect/rosstat_ts/nizhstat/ru/statistics/standards_of_life/ (проверено 04.08.2018). 
Совокупность факторов неудовлетворенности большинства нижегородцев заработком, несомненно, включает сдерживание работодателями роста заработной платы для своих рабочих за счет дешевой импортной рабочей силы. Именно об этом свидетельствуют результаты исследования ВЦИОМа: значительное большинство населения России считает, что работодателям выгоднее брать на работу мигрантов, чем местных жителей $(81 \%)$, поскольку мигранты соглашаются на самую низкую зарплату, что приводит к сдерживанию роста зарплат коренных жителей $(71 \%)^{1}$.

Негативные последствия миграции прослеживаются и в жилищной сфере. В 2016 г. удельный вес семей, состоявших на учете в качестве нуждающихся в жилых помещениях, в общем числе семей ПФО составил 5,4\%. По этому показателю ПФО занимает 3 -е место в России после СКФО $(8,1 \%)$ и СЗФО $(6,1 \%)$. В Нижегородской обл. этот показатель составил 2,9\% (2-е место в ПФО $-2,4 \%)^{2}$. Вместе с тем присутствие значительного числа мигрантов не только повышает спрос, но и неизбежно повышает цены на жилье. Так считает значительная часть населения России $(41 \%)^{3}$. Причем практически каждое четвертое из нижегородских домохозяйств $(24,4 \%)$ находится в стесненных жилищных условиях (см. табл. 5).

Таблица 5

\section{Самооценка степени стесненности жилищных условий нижегородских домохозяйств, \%}

\begin{tabular}{|l|c|c|c|}
\hline \multirow{2}{*}{$\begin{array}{c}\text { Домохозяйства, указавшие, } \\
\text { что при проживании }\end{array}$} & \multirow{2}{*}{ Всего } & \multicolumn{2}{|c|}{ Проживают } \\
\cline { 3 - 4 } & & в городе & в селе \\
\hline не испытывают стесненности & 75,6 & 73,3 & 84,2 \\
\hline испытывают определенную стесненность & 17,8 & 19,6 & 11,3 \\
\hline испытывают большую стесненность & 6,6 & 7,1 & 4,6 \\
\hline
\end{tabular}

Источник: Итоги комплексного наблюдения условий жизни населения в 2016 году. Оценка домохозяйствами состояния занимаемого жилого помещения. - Территориальный орган государственной статистики по Нижегородской области. Уровень жизни. Официальная статистика. 19.12.2017. Доступ: http://nizhstat.gks.ru/wps/wcm/connect/rosstat_ts/nizhstat/ru/statistics/standards_of_life/ (проверено 16.08.2018).

Обостряется ситуация в сфере пассажирских автоперевозок. По числу автобусов общего пользования (120 на 100000 чел. населения) ПФО занимает 4-е место в России после СФО (144), СКФО (135), ЮФО (132). Нижегородская обл. занимает 25-е место в России (135). По числу дорожно-транспортных происшествий и пострадавших в них на 100000 чел. населения ПФО занимает 3-е место в России после ДВФО и СЗФО 4 . При этом значительное большинство нижегородцев пользуются транспортом $(89,8 \%)$, причем $62,2 \%$ из них пользуются общественным транспортом, 38,2\% - коммерческим, 55,6\%

\footnotetext{
1 Мигранты в России: эффекты присутствия. - ВЦИОМ. Пресс-выпуск № 3254. 29.11.2016. Доступ: https://wciom.ru/index.php?id=236\&uid=473 (проверено 04.08.2018).

2 Регионы России. Социально-экономические показатели: статистический сборник. М.: Росстат. 2017. C. 326-327.

3 Мигранты в России: эффекты присутствия. - ВЦИОМ. Пресс-выпуск № 3254. 29.11.2016. Доступ: https://wciom.ru/index.php?id=236\&uid=473 (проверено 17.08.2018).

4 Регионы России. Социально-экономические показатели: статистический сборник. М.: Росстат. 2017. C. $1042-1044$.
} 
пользуются автомобилем или мотоциклом ${ }^{1}$. Представляется достаточно убедительным предположение, что присутствие мигрантов сказывается не только на большей загруженности автодорог, но также и на перегруженности общественного транспорта, создавая дополнительные трудности для принимающего населения.

На 1000 детей дошкольного возраста в ПФО приходится 668 мест в организациях, осуществляющих образовательную деятельность по образовательным программам дошкольного образования, присмотр и уход за детьми. По этому показателю ПФО занимает 4-е место в России после УрФО (707), ДВФО (679), СЗФО (750). Нижегородская обл. занимает по этому показателю 22-е место в России и 9-е место в ПФО 2 . Вместе с тем значительная часть нижегородцев, имеющих детей в возрасте до 15 лет, не имеют финансовых условий, необходимых для полноценного развития детей. Треть нижегородских домохозяйств (свыше 30\%) не может обеспечить детям условия для полноценного развития на платной основе 3 .

Тревожная ситуация складывается в здравоохранении: в 2016 г. по числу больничных коек на 10000 чел. населения ПФО занимал 4-е место в России $(81,5)$. Нижегородская обл. по этому показателю $(87,1)$ занимает 32 -е место в России и 3-е место в ПФО. В ходе выборочного обследования Нижегородоблстата в 2016 г. 36,9\% нижегородцев указали, что при наличии потребности в медицинской помощи не обращались в медицинские организации.

Среди причин «необращения» лидируют неудовлетворенность работой медицинских организаций, а также то, что необходимое лечение можно получить только на платной основе. В связи с этим показательно обращение депутата ГД РФ В. Сысоева к правительству России, в котором отмечается, что при общем сокращении расходов на здравоохранение ежегодно территориальные фонды обязательного медицинского страхования тратят на оказание скорой медицинской помощи трудящимся на территории России иностранным гражданам сотни миллионов рублей. В результате эти средства безвозвратно уходят из бюджетов территориальных фондов ОМС, в то время как могли быть направлены на охрану здоровья российских граждан ${ }^{4}$.

В ходе социологических исследований в Нижегородской обл. установлено, что рост миграционной нагрузки при определенных условиях может повлечь существенное ухудшение функционирования основных подсистем социальной сферы принимающего сообщества 5 .

Следует отметить, что нижегородцы в целом толерантно относятся к мигрантам и миграции в целом: менее $9 \%$ респондентов полагают, что мигранты оказывают сильное влияние на их повседневную жизнь, и почти $50 \%$ участников опроса считают, что мигранты и миграционные процессы почти не влияют

\footnotetext{
1 Итоги комплексного наблюдения условий жизни населения в 2016 году. Транспортное обслуживание. - Территориальный орган государственной статистики по Нижегородской области. Уровень жизни. Официальная статистика. 20.12.2017. Доступ: http://nizhstat.gks.ru/wps/wcm/connect/rosstat_ts/ nizhstat/ru/statistics/standards_of_life/ (проверено 04.08.2018).

2 Регионы России. Социально-экономические показатели: статистический сборник. М.: Росстат. 2017. С. 346-347.

3 Итоги комплексного наблюдения условий жизни населения в 2016 году. Наличие условий для полноценного развития ребенка. - Территориальный орган государственной статистики по Нижегородской области. Уровень жизни. Официальная статистика. 19.12.2017. Доступ: http://nizhstat.gks.ru/wps/wcm/ connect/rosstat_ts/nizhstat/ru/statistics/standards_of_life/ (проверено 04.08.2018).

4 Скорую помощь предлагают сделать платной для мигрантов. - Известия. 14.01.2016. Доступ: https://iz.ru/news/601529 (проверено 17.08.2018).

5 Отчет о научно-исследовательской работе Приволжского филиала ИС РАН в 2014-2016 гг. «Изучение динамики изменений социально-политической ситуации в различных регионах Приволжского федерального округа».
} 
на нее [Самсонов 2018]. Вместе с тем это явление вызывает негативную реакцию части принимающего сообщества, прежде всего молодежи, значительная часть которой негативно относится к мигрантам [Динамика ценностных... 2014: 193].

Значительные масштабы во многом неконтролируемых миграционных потоков в сочетании с нерешенностью проблем жизнеобеспечения значительной части принимающего населения негативно сказывается на социально-экономической и политической ситуации в регионе.

Представляется закономерным, что большинство населения России не поддерживает иммиграционную политику государства. По данным ВЦИОМа, значительное большинство населения России (78\%) считают, что государство должно ограничивать приток иностранных мигрантов в Россию: большинство россиян убеждены, что мигрантов «слишком много»1. Такая политика не имеет серьезной перспективы и может лишь на короткий срок отодвинуть решение назревших социальных проблем региона.

Результаты нашего исследования свидетельствуют, что настоятельно необходимы не только анализ взаимосвязи между институциональной средой и уровнем миграционной нагрузки, но и формирование эффективных механизмов взаимодействия населения с государством, способных влиять на решение подобных проблем.

\section{Список литературы:}

Динамика ценностных ориентаций молодежи (2006-2014 г2.): монография (под общ. ред. Е.П. Савруцкой). 2014. Н. Новгород: Изд-во НГЛУ; СПб: Изд-во РХГА. 232 с.

Дмитриев А.В., Воронов В.В. 2017. Адаптация и интеграция полиэтнического пространства регионов России: проблемы и рекомендации. М.: Новый хронограф. $184 \mathrm{c}$.

Самсонов А.И. 2018. Аналитический обзор материалов опросов общественного мнения, проведенных осенью 2017 и в январе 2018 г2. Приволжским филиалом ФНИСЦ РАН и институтом проблем социального управления. Н. Новгород: ФНИСЦ РАН. Приволжский филиал.

\footnotetext{
${ }^{1}$ Мигранты в России: эффекты присутствия. - ВЦИОМ. Пресс-выпуск № 3254. 29.11.2016. Доступ:
} https://wciom.ru/index.php?id=236\&uid=473 (проверено 17.08.2018). 
USTINKIN Sergei Vasil'evich, Dr.Sci. (Hist.), Dean of the Faculty of International Relations, Economy and Management; Professor of the Chair of International Relations and Political Science, Dobroljubov State Linguistics University of Nizhny Novgorod (31a Minina St, Nizhny Novgorod, Russia, 603155); Director of Volga branch of the Federal Center of Theoretical and Applied Sociology, Russian Academy of Sciences (4 Holodnyi Lane, Nizhny Novgorod, Russia, 603000; sv.ustinkin@gmail.com)

KUKONKOV Pavel Ivanovich, Cand.Sci. (Soc.), Senior Researcher of Volga branch of the Federal Center of Theoretical and Applied Sociology, Russian Academy of Sciences (4 Holodnyi Lane, Nizhny Novgorod, Russia, 603000; kukonkov_ pavel@rambler.ru)

MOROZOVA Natalia Mikhailovna, Cand.Sci. (Pol.Sci), Associate Professor of the Chair of International Relations and Political Science, Dobroljubov State Linguistics University of Nizhny Novgorod (31a Minina St, Nizhny Novgorod, Russia, 603155); Deputy Director of Volga branch of the Federal Center of Theoretical and Applied Sociology, Russian Academy of Sciences (4 Holodnyi Lane, Nizhny Novgorod, Russia, 603000; 4379037@gmail.com)

\title{
MIGRATORY PRESSURE IN THE REGIONS OF VOLGA FEDERAL DISTRICT: SCALES AND CONSEQUENCES
}

\begin{abstract}
The analysis of a social situation in Russian regions not only demands attention to processes of adaptation of migrants, but also needs a special view of these problems from the position of the accepting community. The authors prove an approach according to which migration policy has to be coordinated with development plans for network of social institutions; they also analyze how effective such coordination is on the example of Volga Federal District and the Nizhny Novgorod Region. The authors conclude that considerable scales of uncontrollable migration flows in combination with suspense of problems of life support of a considerable part of the hosting population negatively affect a social, economic and political situation in the region. It demands improving of mechanisms of interaction between population and the state, capable to influence effectively the solution of similar problems.
\end{abstract}

Keywords: social processes, social tension, social conflict, social contradiction, migration, migration policy, hosting community 